\title{
Second Primary Cancer after Diagnosis and Treatment of Cervical Cancer
}

\author{
Myong Cheol Lim, MD, PhD',2 \\ Young-Joo Won, $\mathrm{PhD}^{3}$ \\ Jiwon Lim, MS 3 \\ Yeon-Joo Kim, MD, PhD² \\ Sang Soo Seo, MD, PhD2 \\ Sokbom Kang, MD, $P h D^{1,2}$ \\ Eun Sook Lee, MD, PhD ${ }^{4}$ \\ Jae Hwan Oh, MD, PhD ${ }^{5}$ \\ Joo-Young Kim, MD, PhD² \\ Sang-Yoon Park, MD, PhD',2
}

${ }^{1}$ Gynecologic Cancer Branch,

${ }^{2}$ Center for Uterine Cancer,

${ }^{3}$ Cancer Registration and Statistics Branch,

${ }^{4}$ Center for Breast Cancer,

${ }^{5}$ Center for Colorectal Cancer,

National Cancer Center, Goyang, Korea

\section{Purpose}

This study was conducted to investigate the incidence and survival outcomes of second primary cancers after the diagnosis of cervical cancer.

\section{Materials and Methods}

Data from the Korea Central Cancer Registry between 1993 and 2010 were reviewed and analyzed. Standardized incidence ratios (SIRs) of second primary cancers among women with cervical cancer were analyzed. Kaplan-Meier survival curves were constructed for cervical cancer patients with or without a second primary cancer.

\section{Results}

Among 72,805 women with cervical cancer, 2,678 (3.68\%) developed a second primary cancer within a mean follow-up period of 7.34 years. The overall SIR for a second cancer was 1.08 (95\% confidence interval, 1.04 to 1.12). The most frequent sites of second primary cancers were the vagina, bone and joints, vulva, anus, bladder, lung and bronchus, corpus uteri, and esophagus. However, the incidence rates of four second primary cancers (breast, rectum, liver, and brain) were decreased. The 5-year and 10-year overall survival rates were $78.3 \%$ and $72.7 \%$ in all women with cervical cancer, and for women with a second primary cancer, these rates were $83.2 \%$ and $65.5 \%$ from the onset of cervical cancer and $54.9 \%$ and $46.7 \%$ from the onset of the second primary cancer, respectively.

\section{Conclusion}

The incidence rates of second primary cancers were increased in women with cervical cancer compared to the general population, with the exception of four decreasing cancers. The 10-year overall survival rates were decreased in cervical cancer patients with a second primary cancer.
Correspondence: Young-Joo Won, PhD

National Cancer Center, 323 Ilsan-ro,

Ilsandong-gu, Goyang 10408, Korea

Tel: $82-31-920-2015$

Fax: 82-31-920-2179

E-mail: astra67@ncc.re.kr

Received November 13, 2014

Accepted June 29, 2015

Published Online July 17, 2015
Key words

Second primary neoplasm, Cervix uteri, Neoplasms, Korean

\section{Introduction}

The incidence of cervical cancer has shown a continuous decrease in developed countries, including Korea, however the worldwide burden of cervical cancer remains critical [1-4]. Most cervical cancer survivors face several challenging issues after completion of their primary treatment [5]; in particular, second primary cancers have become a critical issue for cervical cancer survivors as treatment outcomes have improved [6].

A second primary cancer may be related not only to a shared etiology but also to a late effect of treatment [7]. Treatments for cervical cancer have been continuously evolving, leading to improvements in radiotherapy and surgery in terms of instrumentation and minimally invasive surgical approaches. Therefore, updated data on second primary cancers are needed to determine the order of priorities in health care policy and post-treatment surveillance programs. Recent reports on second primary cancers after treatment of cervical 
cancer have focused on the increased risk of cancer [8]. However, premature ovarian failure due to treatment of cervical cancer and the shared radiotherapy field has not been considered or adequately discussed, as this complication may result in a decreased incidence of hormone-dependent cancers and pelvic tumors within the radiotherapy field. Poorer survival outcomes in women with a second primary cancer after the diagnosis and treatment of cervical cancer has been documented [9], although additional investigation regarding detailed survival outcomes according to the type of second primary cancer and survival outcomes from the onset of the second primary cancer is needed in order to obtain better clinical information for such patients. Therefore, the objective of this study was to investigate the incidence and survival outcomes of second primary cancers after the diagnosis and treatment of cervical cancer in a recent study cohort.

\section{Materials and Methods}

This study was approved by the Institutional Review Board (NCC2014-0054). Data from the Korea Central Cancer Registry from 1993 to 2010 identified 72,805 patients with cervical cancer; patients within 2 months of their cervical cancer diagnosis were excluded. To avoid potential confusion, secondary cervical and vaginal cancer cases within 5 years of the diagnosis of primary cervical cancer were excluded. Standardized incidence ratios (SIRs) and the corresponding 95\% confidence intervals (95\% CIs) of second primary cancers among women with cervical cancer were analyzed to quantify the relative risk compared to women in the general population. These SIRs were calculated by dividing the observed number of second cancers by the expected number if the patients in the cohort demonstrated cancer rates equivalent to those for individuals in the general population. The number of person-years at risk (PYRs) was defined from 2 months after the date of the cervical cancer diagnosis to the date of death or the end date of this study, whichever occurred first. For each initial cancer site grouping, the PYRs and observed cases of cancer were stratified according to 5-year age groups and calendar year. Cancer incidence rates were computed for each subsite of cancer and according to age and calendar year, and multiplied by the accumulated PYRs to estimate the expected number of subsequent cancers for each stratum. Kaplan-Meier survival curves were calculated for cervical cancer patients with or without a second cancer. Differences between groups were assessed using a log-rank test. All of the statistical tests were two-sided, and the significance was set at an alpha level of 0.05. The "MP-SIR" setting of SEER ${ }^{*}$ Stat 8.1.2 was used for computation of the SIRs and their 95\% CIs. Survival curves were generated and log-rank tests were performed in Stata ver. 11 (StataCorp., College Station, TX).

\section{Results}

A total of 72,805 women diagnosed with primary invasive cervical cancer were evaluated for a mean follow-up period of 7.34 years (Table 1). The mean age at initial diagnosis with cervical cancer was 51.4 years, and the incidence of cervical cancer diagnosis peaked between the ages of 40 to 59 years $(49.8 \%)$. Of the 72,805 women with cervical cancer, 2,678 women $(3.68 \%)$ developed a second primary cancer; $0.16 \%$ of the women with cervical cancer developed a third or greater primary cancer $(n=119)$. The mean interval from the initial cervical cancer diagnosis to the second cancer diagnosis was 6.3 years, and the mean age at diagnosis with the second primary cancer was 59.4 years. In women with second primary cancer, average age at diagnosis of cervical cancer was higher and follow-up period was longer with statistical significance $(\mathrm{p}<0.05)$.

As shown in Table 2, the overall SIR for a second primary cancer was 1.08 (95\% CI, 1.04 to 1.12), and 1.15 (95\% CI, 1.08 to 1.22$)$ in women aged < 50 years and $1.14(95 \% \mathrm{CI}, 1.08$ to 1.21 ) in women at $<60$ months after diagnosis of the primary cervical cancer. The most frequent sites of second primary cancers that showed significantly higher SIRs for all women were the vagina (9.36), bone and joints (2.70), vulva (2.58), anus (2.42), bladder (2.38), lung and bronchus (2.13), corpus uteri (1.91), and esophagus (1.86).

The risk of a second primary cancer was classified according to age at diagnosis with cervical cancer and follow-up period. The risk of a second primary cancer in the bone and joints (3.87), esophagus (2.61), and soft tissue (2.19) increased significantly after a follow-up period $\geq 60$ months. A leadtime effect was identified for the thyroid, which showed an increase before a follow-up period $<60$ months (1.29) and a decrease after a follow-up period $\geq 60$ months ( 0.88$)$. The risk of a second primary cancer of the vagina (11.6), corpus uteri (3.00), bone and joints (2.76), anus (2.64), bladder (1.84), and lung and bronchus (1.79) increased significantly in women aged $\geq 50$ years.

In contrast, the incidence of a second primary cancer was significantly decreased for breast (0.82), rectum and rectosigmoid junction (0.74), liver (0.64), and brain and central nervous system (0.54) cancers. Diverse patterns of reduction in these second primary cancers were observed depending on the type of cancer. The reduction in breast cancer as a second primary cancer was consistent irrespective of the follow-up 
Table 1. Characteristics of patients with an initial cancer of the cervix according to the second primary cancers, 1993-2010

\begin{tabular}{|c|c|c|c|}
\hline Characteristic & Only subsequent cancers & Only first cervical cancer & Total \\
\hline Women with cervical cancer & $2,678(100)$ & 70,127 (100) & $72,805(100)$ \\
\hline Follow-up (yr) & $9.07 \pm 4.74$ & $7.28 \pm 5.33$ & $7.34 \pm 5.32$ \\
\hline Age at diagnosis with cervical cancer ${ }^{\text {a) }}$ & $53.10 \pm 11.99$ & $51.34 \pm 13.59$ & $51.40 \pm 13.54$ \\
\hline \multicolumn{4}{|l|}{ No. of women by age at 1st primary cancer diagnosis $(y r)^{a)}$} \\
\hline$<30$ & $28(1.05)$ & $1,995(2.84)$ & $2,025(2.78)$ \\
\hline 30-39 & $352(13.14)$ & $13,123(18.71)$ & $13,477(18.51)$ \\
\hline $40-49$ & $723(27.00)$ & $19,496(27.80)$ & $20,219(27.77)$ \\
\hline $50-59$ & $720(26.89)$ & $15,321(21.85)$ & $16,042(22.03)$ \\
\hline $60-69$ & $593(22.14)$ & $12,287(17.52)$ & $12,880(17.69)$ \\
\hline $70-79$ & $242(9.04)$ & $6,373(9.09)$ & $6,612(9.08)$ \\
\hline$\geq 80$ & $20(0.75)$ & $1,532(2.18)$ & $1,550(2.13)$ \\
\hline No. of women who developed a 2 nd primary cancer & $2,678(3.68)$ & - & - \\
\hline 1st and 2 nd cancers & $2,559(3.51)$ & - & - \\
\hline 1st, 2 nd, and 3rd cancers & $114(0.16)$ & - & - \\
\hline 1st, 2 nd, 3rd, and additional cancers & $5(0.01)$ & - & - \\
\hline Interval between 1st and 2nd cancers (yr) & $6.30 \pm 4.41$ & - & - \\
\hline Age at diagnosis of $2 \mathrm{nd}$ cancer $(\mathrm{yr})$ & $59.41 \pm 12.30$ & - & - \\
\hline
\end{tabular}

Values are presented as number $(\%)$ or mean \pm standard deviation. ${ }^{a}$ Significant at $\alpha=0.05$.

period, but only for women aged $<50$ years. Specifically, SIR decreased significantly for women aged $40-49$ years (0.77) but did not reach statistical significance for women aged 50 59 years (0.82) and 60-69 years (0.85). For rectal cancers and rectosigmoid junction cancers (RSCs), the reduction in incidence was significant only for a follow-up period $<60$ months in women aged $\geq 50$ years. The risk of liver cancer as the second primary tumor was decreased for follow-up periods $\geq 60$ months and in women aged $\geq 50$ years. Last, a significant reduction in the incidence of a second primary cancer in the brain and central nervous system was observed in women aged $\geq 50$ years.

The 5-year and 10-year overall survival rates from the onset of cervical cancer (Fig. 1A) were $78.3 \%$ and $72.7 \%$ in all women with cervical cancer, respectively. Among all women, significantly higher survival was observed in patients aged $<50$ years $(\mathrm{p}<0.001$ ); the 5-year and 10-year overall survival rates were $86.8 \%$ and $84.4 \%$ for women aged $<50$ years and $78.3 \%$ and $61.2 \%$ for women aged $\geq 50$ years, respectively. For women with a second primary cancer, the 5-year and 10-year overall survival rates (Fig. 1B) were 83.2\% and $65.5 \%$, respectively. In these women, significantly higher survival was observed in patients aged $<50$ years $(\mathrm{p}<0.001)$, and the 5-year and 10-year overall survival rates were $88.6 \%$ and $76.8 \%$ for women aged $<50$ years and $83.2 \%$ and $57.8 \%$ for women aged $\geq 50$ years, respectively. A higher 5-year overall survival rate was observed in patients with a second primary cancer, but the 10-year overall survival rate was lower in patients with a second primary cancer $(\mathrm{p}<0.001)$.
The 10-year survival rate sharply declined after diagnosis with cervical cancer in the second primary cancer group compared to the no second primary cancer group. The overall survival rates were $86.3 \%$ and $95.0 \%$ at 2 years, $78.1 \%$ and $83.2 \%$ at 5 years, and $73.1 \%$ and $65.5 \%$ at 10 years in the no second primary cancer group and the second primary cancer group, respectively (Fig. 2).

The 5-year and 10-year overall survival rates from the onset of the second primary cancer (Fig. 3A) were $54.9 \%$ and $46.7 \%$ in patients with a second primary cancer, respectively. Significantly higher survival was observed in women $<50$ years ( $p<0.001$ ), and the 5-year and 10-year overall survival rates were $71.7 \%$ and $67.5 \%$ for women aged $<50$ years and $54.9 \%$ and $39.1 \%$ for women aged $\geq 50$ years, respectively. Specifically, the 5-year and 10-year overall survival rates from the onset of the second primary cancer (Fig. 3B) were as follows: $83.8 \%$ and $75.4 \%$ for the breast, $56.1 \%$ and $53.6 \%$ for the rectum, $21 \%$ and $21 \%$ for the liver, $23.2 \%$ and $18.4 \%$ for the lung and bronchus, $46.9 \%$ and $36.9 \%$ for the bladder, and $37.0 \%$ and $21.4 \%$ for the corpus uteri, respectively.

\section{Discussion}

In the current study, the incidence of a second primary cancer after diagnosis and treatment of cervical cancer was increased compared to the general population (SIR, 1.08), 


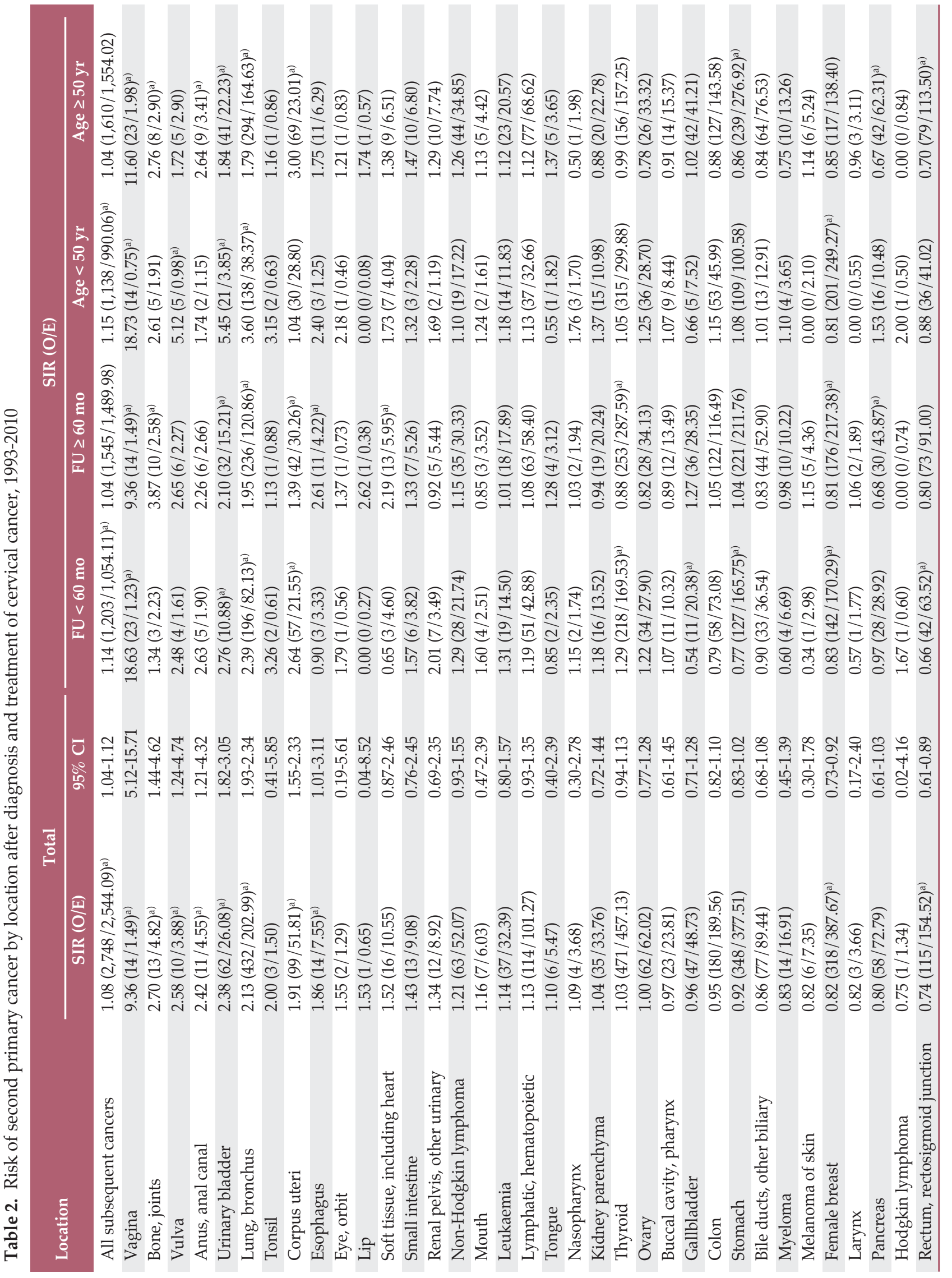




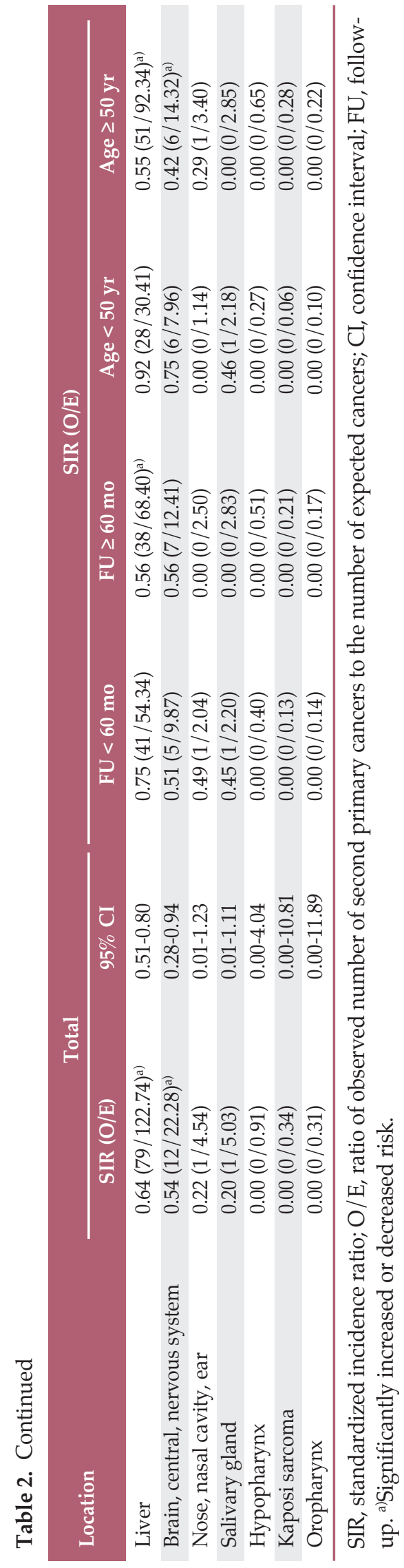

which is consistent with several previous reports [6,8-15]. Further studies and strategies on the second primary cancer after cervical cancer should be considered in terms of shared etiology with cervical cancer or as a late effect of treatment for cervical cancer. Well-known contributing factors for cervical cancer include the human papillomavirus (HPV) and smoking. In the current study, HPV-related cancers, including those of the vagina, vulva, or anus, and smoking-related cancers, such as cancers of the lung and bronchus, bladder, or esophagus cancer were increased. This finding was consistent with previous study results and has been well investigated [6,8-15].

Late effects of radiotherapy for second primary tumors have recently been reported $[7,8]$. Radiotherapy increased the risk of middle- and lower-portion stomach cancer (odds ratio, 4.20) after a dose $\geq 5$ Gy for cervical cancer, according to a study performed in five Western countries [7]. With any radiotherapy for cervical cancer, the risk of stomach cancer increases (SIR, 1.31) according to a collaborative study between Europe and the United States [8]. However, in the current study, the overall risk of stomach cancer after treatment for cervical cancer was not different from the risk in healthy Korean women. This finding may be explained by racial differences and the significantly higher incidence of stomach cancer in Korea (fifth ranked cancer; estimated new cases in 2013, 10,623; and age-standardized cancer incidence, $42.1 / 100,000$ ) compared to the United States (the estimated number of new cases in women in 2013 was 8,370), especially considering that Korea has $1 / 6$ the population of the United Staes [1,2].

In the current study, four cancers showed decreased incidence after the diagnosis and treatment of cervical cancer, including breast, rectum, liver, and brain cancers. First, the incidence of breast cancer was significantly decreased after the diagnosis and treatment of cervical cancer (SIR, 0.82; 95\% $\mathrm{CI}, 0.73$ to 0.92$)$. In the case of surgical treatment for cervical cancer, oophorectomy may be incorporated with radical hysterectomy, and ovarian function has been shown to fail early after hysterectomy, even with ovarian preservation [16]. In the case of radiotherapy for locally advanced cervical cancer, the ovaries are ablated because they share the radiotherapy field with the pelvic lymph nodes [17]. After primary treatment for cervical cancer, irrespective of the treatment type, ovarian function deteriorates $[16,17]$. Therefore, the observed decrease in the incidence of breast cancer as a second primary cancer can likely be explained by decreased ovarian cancer related to cervical cancer treatment. In particular, this reduction was limited to premenopausal women (aged $<50$ years) considering the median age of menopause in Korean women but was independent of the follow-up period [18]. Deteriorated ovarian function with cervical cancer treatment results in a trend of decreasing breast cancer 

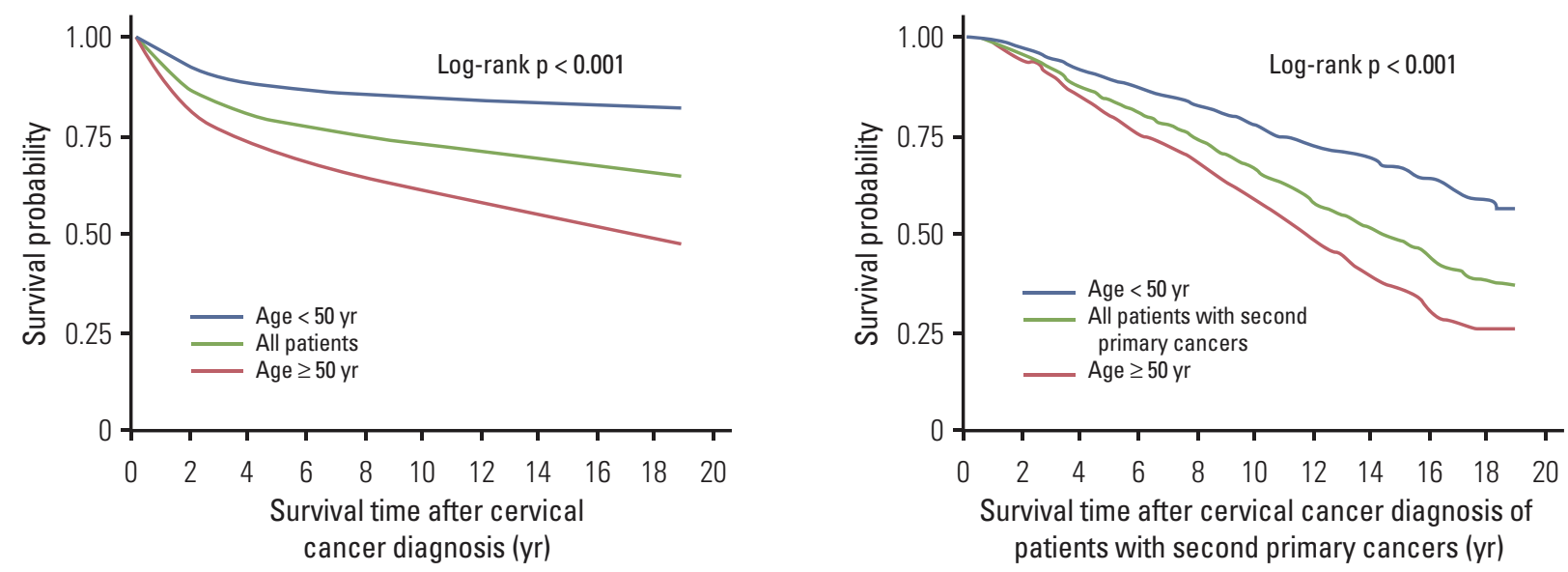

\begin{tabular}{cccc}
\multicolumn{4}{c}{ Survival probability (\%) } \\
$\begin{array}{c}\text { Survival } \\
\text { (yr) }\end{array}$ & $\begin{array}{c}<0 \mathrm{yr} \\
(\mathrm{n}=35,721)\end{array}$ & $\begin{array}{c}\geq 5 \mathrm{yr} \\
(\mathrm{n}=37,084)\end{array}$ & $\begin{array}{c}\text { All } \\
(\mathrm{n}=72,805)\end{array}$ \\
\hline 1 & 96.4 & 89.5 & 92.9 \\
2 & 92.1 & 81.3 & 86.6 \\
3 & 89.6 & 76.2 & 82.8 \\
4 & 88.0 & 72.6 & 80.1 \\
\hline 5 & 86.8 & 78.3 & 78.3 \\
7 & 85.6 & 66.1 & 75.7 \\
10 & 84.4 & 61.2 & 72.7 \\
15 & 82.9 & 53.5 & 68.1 \\
18 & 81.9 & 49.3 & 65.3 \\
\hline
\end{tabular}

\begin{tabular}{|c|c|c|c|}
\hline \multicolumn{4}{|c|}{ Survival probability (\%) } \\
\hline $\begin{array}{c}\text { Survival } \\
\text { (yr) }\end{array}$ & $\begin{array}{c}<50 y r \\
(n=1,103)\end{array}$ & $\begin{array}{c}\geq 50 y r \\
(n=1,575)\end{array}$ & $\begin{array}{c}\text { All } \\
(n=2,678)\end{array}$ \\
\hline 1 & 98.9 & 97.7 & 98.2 \\
\hline 2 & 96.4 & 94.0 & 95.0 \\
\hline 3 & 93.5 & 89.3 & 91.0 \\
\hline 4 & 91.3 & 83.7 & 86.8 \\
\hline 5 & 88.6 & 83.2 & 83.2 \\
\hline 7 & 84.6 & 71.8 & 77.1 \\
\hline 10 & 76.8 & 57.8 & 65.5 \\
\hline 15 & 66.3 & 35.2 & 47.4 \\
\hline 18 & 58.4 & 25.4 & 37.9 \\
\hline
\end{tabular}

Fig. 1. Survival outcomes from the onset of cervical cancer according to age at cervical cancer onset (age $<50$ years vs. age $\geq 50$ years) in all women with cervical cancer (A) and in women with a second primary cancer (B).

but this does not reach statistical significance.

The second type of second primary cancer found to show a decreased incidence was rectal cancer and RSC. RSC decreased significantly until 5 years after the diagnosis and treatment of the initial cervical cancer (SIR, $0.66 ; 95 \%$ CI, 0.48 to 0.89 ), whereas at 5 years after the diagnosis and treatment of cervical cancer, the preventive effect for RSC was no longer identified (SIR, $0.80 ; 95 \%$ CI, 0.63 to 1.01). This finding may be explained by the shared radiotherapy field that may cause ablation of microscopic or early rectal cancer [19]. The rectosigmoid mucosa is known to be affected by radiotherapy [19]. In contrast, the risk of rectal cancer showed a significant increase (SIR, 1.90) after radiotherapy for cervical cancer in women from Europe and the United States [8]. This result might have been caused by the following issues. First, the follow-up period after the diagnosis of cervical cancer was not considered in that study [8], and the SIR might vary during different periods. Second, treatment outcomes after radiotherapy for RSC greatly differ according to racial and ethnic disparities among whites, Hispanics, and Asians [20]. Third, existence of racial disparities in terms of survival outcomes for cervical cancer have been suggested, according to the Surveillance, Epidemiology, and End Results (SEER) Program data in the United States [21]. Therefore, these differences may affect the pattern of second primary cancers in cancer survivors because a second primary cancer can only be identified in cancer survivors.

The third cancer found to have a decreased incidence was liver cancer (SIR, $0.64 ; 95 \%$ CI, 0.51 to 0.80 ), and this decreasing effect was observed $\geq 60$ months after diagnosis with cervical cancer. It is difficult to intuitively explain the decreased incidence of liver cancer after the diagnosis and treatment of cervical cancer considering the nature of the treatment for cervical cancer and the etiology of liver cancer. Common 


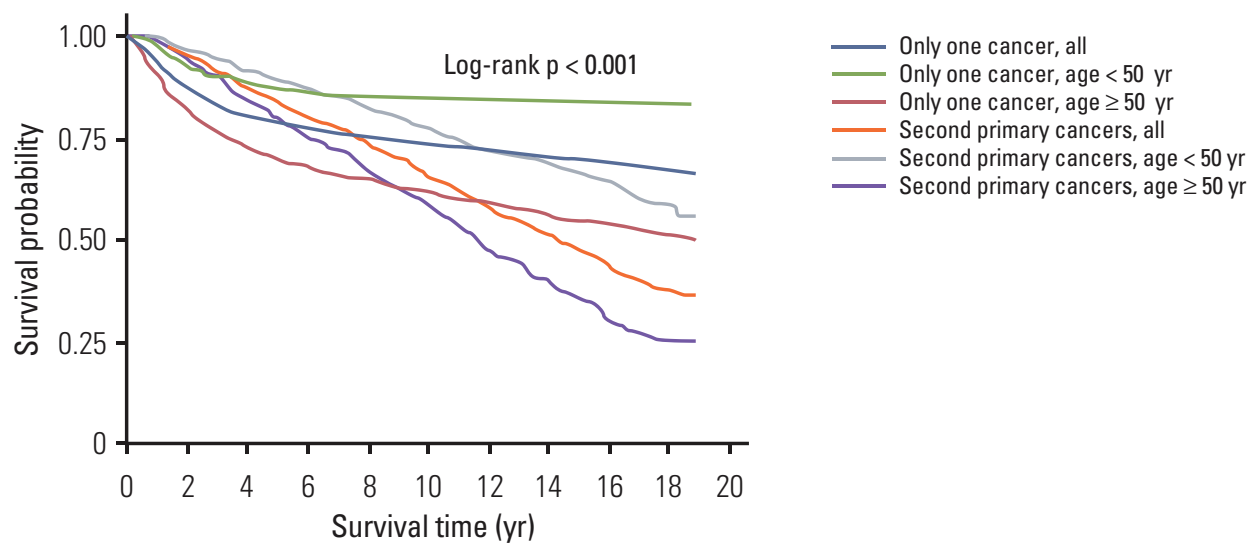

Survival probability $(\%)$

\begin{tabular}{|c|c|c|c|c|c|c|}
\hline \multirow[b]{2}{*}{$\begin{array}{c}\text { Survival } \\
\text { (yr) }\end{array}$} & \multicolumn{3}{|c|}{ Only one primary cancer } & \multicolumn{3}{|c|}{ Second primary cancer } \\
\hline & $\begin{array}{c}<50 y r \\
(n=34,618)\end{array}$ & $\begin{array}{c}\geq 50 y r \\
(n=35,509)\end{array}$ & $\begin{array}{c}\text { All } \\
(\mathrm{n}=70,127)\end{array}$ & $\begin{array}{c}<50 y r \\
(n=1,103)\end{array}$ & $\begin{array}{c}\geq 50 y r \\
(n=1,575)\end{array}$ & $\begin{array}{c}\text { All } \\
(n=2,678)\end{array}$ \\
\hline 1 & 96.3 & 89.1 & 92.7 & 98.9 & 97.7 & 98.2 \\
\hline 2 & 91.9 & 80.8 & 86.3 & 96.4 & 94.0 & 95.0 \\
\hline 3 & 89.4 & 75.6 & 82.4 & 93.5 & 89.3 & 91.0 \\
\hline 4 & 87.9 & 72.1 & 79.9 & 91.3 & 83.7 & 86.8 \\
\hline 5 & 86.8 & 69.6 & 78.1 & 88.6 & 79.4 & 83.2 \\
\hline 7 & 85.7 & 65.9 & 75.7 & 84.6 & 71.8 & 77.1 \\
\hline 10 & 84.7 & 61.5 & 73.1 & 76.8 & 57.8 & 65.5 \\
\hline 15 & 83.7 & 54.9 & 69.3 & 66.3 & 35.2 & 47.4 \\
\hline
\end{tabular}

Fig. 2. Survival outcomes from the onset of cervical cancer according to age at cervical cancer onset (age $<50$ years vs. age $\geq 50$ years) in all women with only cervical cancer or in women with a second primary cancer.

causes of liver cancer include hepatitis, alcoholism, and aflatoxin [22]. Considering the etiology of liver cancer, a certain percentage of liver cancers may be avoided and prevented with the modification of health behaviors, and cancer survivors generally adopt good health behaviors [23]. Therefore, the decreased incidence of liver cancer, especially $\geq 60$ months after the diagnosis of cervical cancer, could be explained by the improved health behaviors in survivors after the diagnosis and treatment of cervical cancer.

The fourth type of second primary cancer that showed a decreased incidence was cancer of the brain and central nervous system (SIR, $0.54 ; 95 \%$ CI, 0.28 to 0.94 ). The entire expected and observed incidence was less than 25, with an SIR of $0.54(12 / 22.28)$. Considering that a significant portion of brain tumors are diagnosed based on imaging studies only, some portion of brain tumors might be classified as brain metastasis in women with a history of cervical cancer. Therefore, this finding should be confirmed in a larger population study.

Poor survival outcomes for second primary cancers have been well investigated [9], and the current study sought to investigate these survival outcomes from a new perspective. First, we found that the survival outcome was poorer among cervical cancer patients with a second primary cancer compared to cervical cancer patients without a second primary cancer, but only after 10 years or more since the diagnosis of cervical cancer. This delay may be explained by the fact that women with early mortality due to cervical cancer do not have a chance to develop a second primary tumor. Second, our study was the first to analyze survival outcomes after the diagnosis of second primary cancer, and detailed survival outcomes after the diagnosis of a second primary cancer were described according to the type of second primary cancer. This information will likely be helpful for discussions with patients about survival outcomes and surveillance.

The main weakness of the current study was the limited 
A

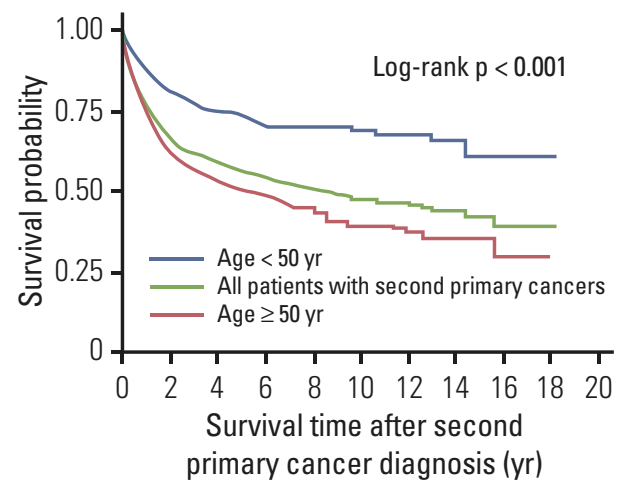

\begin{tabular}{|cccc}
\multicolumn{4}{c}{ Survival probability (\%) } \\
$\begin{array}{c}\text { Survival } \\
\text { (yr) }\end{array}$ & $\begin{array}{c}<50 \mathrm{yr} \\
(\mathrm{n}=641)\end{array}$ & $\begin{array}{c}\geq 50 \mathrm{yr} \\
(\mathrm{n}=2,037)\end{array}$ & $\begin{array}{c}\text { All } \\
(\mathrm{n}=2,678)\end{array}$ \\
\hline 1 & 85.5 & 72.6 & 75.8 \\
\hline 2 & 79.5 & 60.9 & 65.4 \\
\hline 3 & 75.5 & 55.4 & 60.3 \\
\hline 4 & 72.9 & 52.5 & 57.5 \\
\hline 5 & 71.7 & 54.9 & 54.9 \\
7 & 68.4 & 44.9 & 50.8 \\
10 & 67.5 & 39.1 & 46.7 \\
15 & 59.5 & 35.0 & 41.5 \\
18 & 59.5 & 29.2 & 38.3 \\
\hline
\end{tabular}

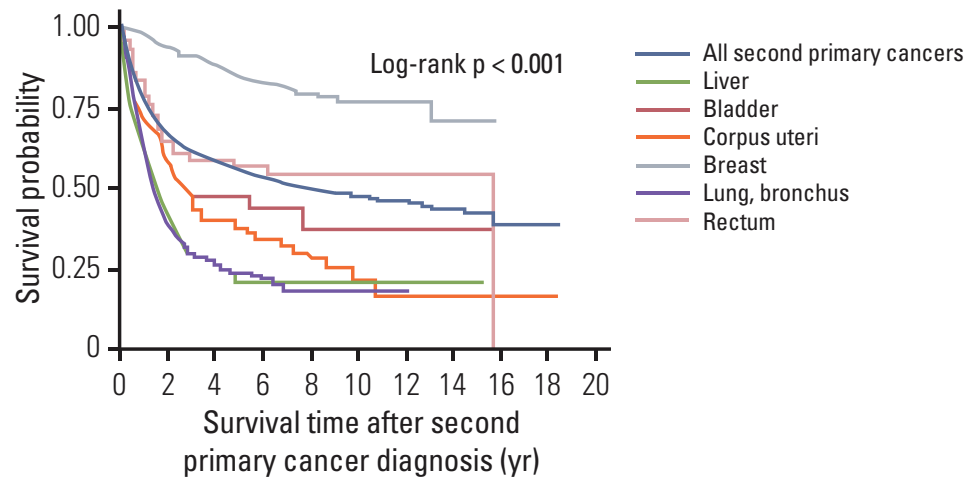

\begin{tabular}{cccccccc}
\multicolumn{7}{c}{ Survival probability (\%) } \\
$\begin{array}{c}\text { Survival } \\
\text { (yr) }\end{array}$ & $\begin{array}{c}\text { Second primary } \\
\text { cancers } \\
(\mathrm{n}=2,678)\end{array}$ & $\begin{array}{c}\text { Breast } \\
(\mathrm{n}=308)\end{array}$ & $\begin{array}{c}\text { Rectum } \\
(\mathrm{n}=96)\end{array}$ & $\begin{array}{c}\text { Liver } \\
(\mathrm{n}=78)\end{array}$ & $\begin{array}{c}\text { Lung, } \\
\text { bronchus } \\
(\mathrm{n}=415)\end{array}$ & $\begin{array}{c}\text { Bladder } \\
(\mathrm{n}=58)\end{array}$ & $\begin{array}{c}\text { Corpus } \\
\text { uteri } \\
(\mathrm{n}=92)\end{array}$ \\
\hline 1 & 75.8 & 95.8 & 77.7 & 61.3 & 57.4 & 67.3 & 73.0 \\
2 & 65.4 & 92.0 & 64.4 & 41.7 & 37.2 & 55.8 & 56.3 \\
3 & 60.3 & 89.6 & 59.4 & 28.4 & 29.6 & 49.4 & 43.8 \\
4 & 57.5 & 87.2 & 58.0 & 26.3 & 26.1 & 46.9 & 39.9 \\
5 & 54.9 & 83.8 & 56.1 & 21.0 & 23.2 & 46.9 & 37.0 \\
7 & 50.8 & 80.1 & 53.6 & 21.0 & 18.4 & 43.0 & 32.0 \\
10 & 46.7 & 75.4 & 53.6 & 21.0 & 18.4 & 36.9 & 21.4 \\
15 & 41.5 & 69.6 & 53.6 & 21.0 & - & 36.9 & 16.0 \\
18 & 38.3 & - & - & - & - & - & 16.0 \\
\hline
\end{tabular}

Fig. 3. Survival outcomes from the onset of the second primary cancer according to age at cervical cancer onset (age $<50$ years vs. age $\geq 50$ years) in women with second primary cancers (A) and at identified second primary cancer in the breast, rectum, liver, lung and bronchus, bladder, and corpus uteri (B).

information on the type of cervical cancer treatment and staging information, which were similar to the disadvantages reported in previous studies [6,8-15]. Another limitation is surveillance bias, which is caused by an effort to detect second cancers in patients with primary cancer. That is, survival (78.3\%) and follow-up (7.28 years) of patients initially diagnosed with one primary cancer would be considerably shorter because they could have a more distant stage than patients diagnosed with second primary cancers (survival, 83.2\%; follow-up, 9.07 years).

\section{Conclusion}

The incidence of a second primary cancer increased after the diagnosis and treatment of cervical cancer, with an SIR of 1.08 (95\% CI, 1.04 to 1.12 ). Among 72,805 women with cervical cancer, 2,678 (3.68\%) developed a second primary cancer. HPV-, smoking-, and treatment-related cancers were frequently identified in the vagina, bone and joints, vulva, anus, bladder, lung and bronchus, corpus uteri, and esophagus. In contrast, the incidence rates of four types of second primary cancers (breast, rectum and rectosigmoid junction, liver, and brain and central nervous system) were significantly decreased. These results suggest the need for conduct of further studies and continued cancer surveillance among cervical cancer survivors. For women with cervical cancer, the 10-year overall survival was poorer in cases with a second primary cancer. 


\section{Conflicts of Interest}

Conflict of interest relevant to this article was not reported.

\section{Acknowledgments}

This study was supported by a National Cancer Center Grant (NCC-1310220).

\section{References}

1. Siegel R, Naishadham D, Jemal A. Cancer statistics, 2013. CA Cancer J Clin. 2013;63:11-30.

2. Jung KW, Won YJ, Kong HJ, Oh CM, Seo HG, Lee JS. Prediction of cancer incidence and mortality in Korea, 2013. Cancer Res Treat. 2013;45:15-21.

3. Forman D, de Martel C, Lacey CJ, Soerjomataram I, LortetTieulent J, Bruni L, et al. Global burden of human papillomavirus and related diseases. Vaccine. 2012;30 Suppl 5:F12-23.

4. Lim MC, Moon EK, Shin A, Jung KW, Won YJ, Seo SS, et al. Incidence of cervical, endometrial, and ovarian cancer in Korea, 1999-2010. J Gynecol Oncol. 2013;24:298-302.

5. Le Borgne G, Mercier M, Woronoff AS, Guizard AV, Abeilard E, Caravati-Jouvenceaux A, et al. Quality of life in long-term cervical cancer survivors: a population-based study. Gynecol Oncol. 2013;129:222-8.

6. Kleinerman RA, Boice JD Jr, Storm HH, Sparen P, Andersen A, Pukkala E, et al. Second primary cancer after treatment for cervical cancer: an international cancer registries study. Cancer. 1995;76:442-52.

7. Kleinerman RA, Smith SA, Holowaty E, Hall P, Pukkala E, Vaalavirta L, et al. Radiation dose and subsequent risk for stomach cancer in long-term survivors of cervical cancer. Int J Radiat Oncol Biol Phys. 2013;86:922-9.

8. Chaturvedi AK, Engels EA, Gilbert ES, Chen BE, Storm H, Lynch CF, et al. Second cancers among 104,760 survivors of cervical cancer: evaluation of long-term risk. J Natl Cancer Inst. 2007;99:1634-43.

9. Chen CY, Lai CH, Lee KD, Huang SH, Dai YM, Chen MC. Risk of second primary malignancies in women with cervical cancer: a population-based study in Taiwan over a 30-year period. Gynecol Oncol. 2012;127:625-30.

10. Boice JD Jr, Blettner M, Kleinerman RA, Stovall M, Moloney WC, Engholm G, et al. Radiation dose and leukemia risk in patients treated for cancer of the cervix. J Natl Cancer Inst. 1987;79:1295-311.

11. Fisher G, Harlow SD, Schottenfeld D. Cumulative risk of second primary cancers in women with index primary cancers of uterine cervix and incidence of lower anogenital tract cancers, Michigan, 1985-1992. Gynecol Oncol. 1997;64:213-23.

12. Nakano T, Kato S, Ohno T, Tsujii H, Sato S, Fukuhisa K, et al. Long-term results of high-dose rate intracavitary brachytherapy for squamous cell carcinoma of the uterine cervix. Cancer. 2005;103:92-101.
13. Ota T, Takeshima N, Tabata T, Hasumi K, Takizawa K. Treatment of squamous cell carcinoma of the uterine cervix with radiation therapy alone: long-term survival, late complications, and incidence of second cancers. Br J Cancer. 2007;97: 1058-62.

14. Tominaga K, Koyama Y, Sasagawa M, Obata N, Kamata H, Yamaguchi E, et al. A follow-up study of patients with cervical cancer after resection, with special emphasis on the incidence of second primary cancers. Gynecol Oncol. 1995;56:71-4.

15. Underwood JM, Rim SH, Fairley TL, Tai E, Stewart SL. Cervical cancer survivors at increased risk of subsequent tobaccorelated malignancies, United States 1992-2008. Cancer Causes Control. 2012;23:1009-16.

16. Moorman PG, Myers ER, Schildkraut JM, Iversen ES, Wang F, Warren N. Effect of hysterectomy with ovarian preservation on ovarian function. Obstet Gynecol. 2011;118:1271-9.

17. Hwang JH, Yoo HJ, Park SH, Lim MC, Seo SS, Kang S, et al. Association between the location of transposed ovary and ovarian function in patients with uterine cervical cancer treated with (postoperative or primary) pelvic radiotherapy. Fertil Steril. 2012;97:1387-93.

18. Schildkraut JM, Cooper GS, Halabi S, Calingaert B, Hartge P, Whittemore AS. Age at natural menopause and the risk of epithelial ovarian cancer. Obstet Gynecol. 2001;98:85-90.

19. Kim TH, Kim JY, Sohn DK, Kim YJ, Lee YS, Moon SH, et al. A prospective observational study with dose volume parameters predicting rectosigmoidoscopic findings and late rectosigmoid bleeding in patients with uterine cervical cancer treated by definitive radiotherapy. Radiat Oncol. 2013;8:28.

20. Lee W, Nelson R, Akmal Y, Mailey B, McKenzie S, Artinyan A, et al. Racial and ethnic disparities in outcomes with radiation therapy for rectal adenocarcinoma. Int J Colorectal Dis. 2012;27:737-49.

21. Rauh-Hain JA, Clemmer JT, Bradford LS, Clark RM, Growdon WB, Goodman A, et al. Racial disparities in cervical cancer survival over time. Cancer. 2013;119:3644-52.

22. Shiraha H, Yamamoto K, Namba M. Human hepatocyte carcinogenesis (review). Int J Oncol. 2013;42:1133-8.

23. Oh MG, Han MA, Park J, Ryu SY, Park CY, Choi SW. Health behaviors of cancer survivors: the Fourth Korea National Health and Nutrition Examination Survey (KNHANES IV, 2007-09). Jpn J Clin Oncol. 2013;43:981-7. 